\title{
Verification of the Effect of Improving Walking Ability on Hemiplegia by Using a Device for Reducing Muscle Tone
}

\author{
Hirofumi Tanabe ${ }^{1 *}$, Akira Kusano1, Hiroshi Tanabe1, Yoshifumi Morita ${ }^{2}$, Yuichi Takata ${ }^{3}$ \\ ${ }^{1}$ Department of Rehabilitation, Shonan University of Medical Sciences, Kanagawa, Japan \\ ${ }^{2}$ Department of Electrical and Mechanical Engineering, Nagoya Institute of Technology, Aichi, Japan \\ ${ }^{3}$ Department of Human Sciences, Hokkaido Bunkyo University, Hokkaido, Japan \\ Email: `hirofumi.tanabe@sums.ac.jp, morita@nitech.ac.jp, takata@do-bunkyodai.ac.jp
}

How to cite this paper: Tanabe, H., Kusano, A., Tanabe, H., Morita, Y. and Takata, Y. (2020) Verification of the Effect of Improving Walking Ability on Hemiplegia by Using a Device for Reducing Muscle Tone. Health, 12, 317-323.

https://doi.org/10.4236/health.2020.124026

Received: March 13, 2020

Accepted: April 14, 2020

Published: April 17, 2020

Copyright (อ 2020 by author(s) and Scientific Research Publishing Inc. This work is licensed under the Creative Commons Attribution International License (CC BY 4.0).

http://creativecommons.org/licenses/by/4.0/ The number of patients with cerebrovascular disease in Japan in 2017 has (c) (i) Open Access

\section{Keywords}

Device, Gait, Step Length, Hemiplegia

\section{Introduction}

\begin{abstract}
We evaluated the efficacy of the piston device simulating manual piston technique for hip joints (PTH) on 8 spastic hemiplegia patients suffering from a limited range of hip joint extension. Results confirmed rapid improvement of hip joint range of motion and increase in the results of the Time up and Go test and walking speed.
\end{abstract} reached about 1.1 million [1]. More than $60 \%$ of patients with hemiplegia after stroke have long-term inconvenience in daily activities [2]. Especially, reduced lower limb motor function limits movement-related activities [3] [4]. Since loss of walking ability is a major problem after Stroke [5] [6], recovery of walking is a priority goal for most patients [7] [8]. Friedman showed that the sooner the individual with a history of stroke attained the ability to ambulate, the more likely it was that independent walking would be re-established [6]. Rehabilitation training is essential in increasing the walking speed of patients with spastic hemiplegia. Reasons for a loss of walking speed in hemiplegia patients include shortening of step width following a period of standing. This occurs because hip joint flexor spasticity and flexor contraction are responsible for producing range in hip joint extension, and standing prevents the hip joint from extending [9]. 
Most stroke patients are reduced walking speed and longer stance phases, greater on the unaffected side, are reported [10]. The first author of this report, an occupational therapist, developed a novel treatment methodology known as PTH designed to increase range of motion during hip joint extension. This treatment can immediately improve spastic weakening and contraction of the hip joint flexor responsible for producing loss of spastic side hip joint extension range in those with spastic hemiplegia. This piston technique was developed to improve the spastic weakening and contraction of digit flexors in spastic hands, and the efficacy of this treatment was also currently being studied [11]. As shown in Figure 1, the hip joint piston technique involves an approximate $1 \mathrm{~cm}$ vertical vibration of the femoral head in the posterior (dorsal) direction for about 10 cycles at a frequency of 5 cycles per second (5 [Hz]). However, this manual technique would overwork a therapist and be difficult to perform on individuals with large bodies. For this reason, a piston device for hip joint $(\mathrm{PDH})$ was developed to simulate this technique.

In this study, $\mathrm{PDH}$ was performed on spastic hemiplegia patients suffering from limited hip joint extension range of motion. Moreover, we investigated the positive effects on hip extension range of motion and walking speed.

\section{Method}

In order to verify the effectiveness of the developed $\mathrm{PDH}$, a clinical study was
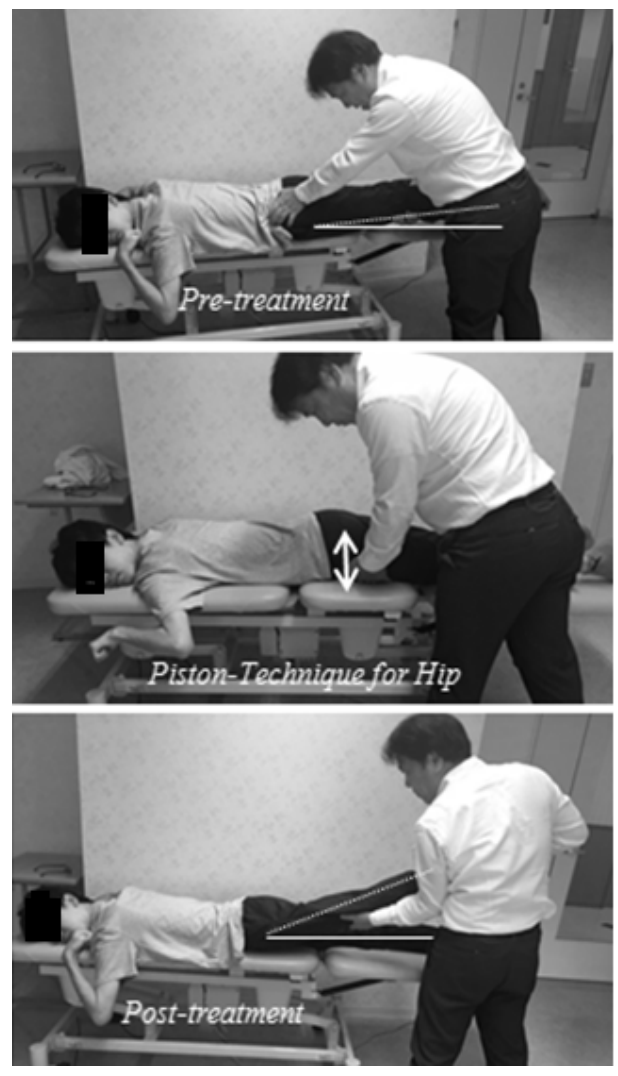

Figure 1. State of treatment of PTH. 
conducted on eight persons with spastic hemiplegia and extension limited in the hip joint. Subjects were recruited via the internet. Inclusion criteria: that six months had passed since the occurrence of a stroke, that there was a limited range of extension for the hip joints, that there was no aching in the extremities, and that the subject be able to assume a prone position. Of the 10 subjects who were recruited, two who were unable to assume a prone position were excluded, leaving 8 subjects. The subjects participated in a one-day clinical study from January 2020 at the clinic where the first author worked. For the therapy, the subjects were first asked to assume a prone position on an examination bed, and they were made to lay in such a way that their hip joints slightly protruded from the edge. The therapist then moved the upper part of the PDH to a position $5 \mathrm{~cm}$ in the distal direction from the hip joint. The therapist held down the patient's paralyzed foot on the brace of the PDH and gradually increased the speed of a reciprocating motion from a stopped state while confirming the effects of the treatment. PDH treatment is shown in Figure 2. The therapist set the rotational speed to $300[\mathrm{rpm}]$ which corresponds to a frequency of $5[\mathrm{~Hz}]$ and the length of the crank arm to $0.02[\mathrm{~m}]$ which corresponds to a stroke of $0.04[\mathrm{~m}]$. The treatment time was approximately 60 seconds depending on the patient's condition of spastic paralysis. The speed during PDH treatment was five cycles per second. The therapist stopped the PDH when judging that it had an effect. The effects of $\mathrm{PDH}$ treatment were assessed using passive range of motion (Passive-ROM) test [12] and the 10 Meter Walk Test [13] [14] and Time Up and Go Test [15] before and after treatment. This study has been approved by the research ethics committee of Shonan University of medical science (17-001).

\section{Results}

The study was completed by 8 participants. The results are summarized in Table 1. Passive-ROM increased range of motion in all participants. Pre-treatment hip joint extension had a mean of 3.1 degrees (standard deviation of 3.7), but post-treatment extension improved to a mean of 20.0 degrees (standard deviation of 6.5). The 10 Meter Walk Test also showed improvement in all participants. Pre-treatment mean duration was 16.4 seconds (standard deviation of 4.5), but

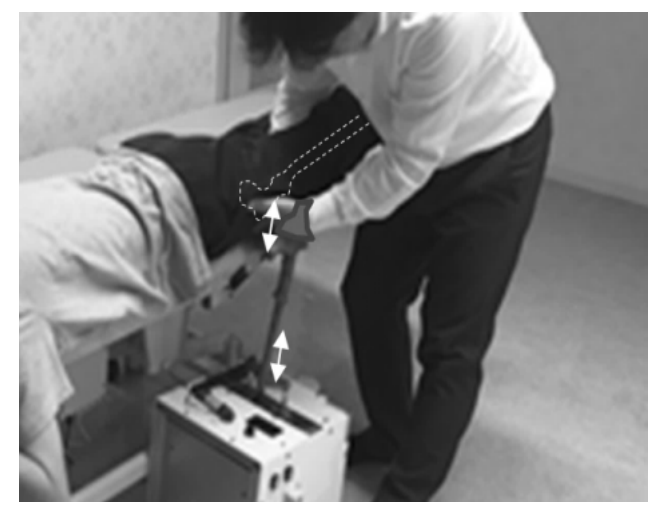

Figure 2. Prototype of the PDH. 
post-treatment duration improved to a mean of 13.5 seconds (standard deviation of 3.6). And Time Up and Go Test showed improvement in 7 out of 8 patients. Pre-treatment mean duration was 16.6 seconds (standard deviation of 3.3), but post-treatment duration improved to a mean of 13.8 seconds (standard deviation of 2.3) (see chart and Figure 3). All results also had significant differences

Table 1. Summary of results.

\begin{tabular}{ccccccc}
\hline \multirow{2}{*}{ No } & \multicolumn{2}{c}{ Hip extension ROM } & \multicolumn{2}{c}{$10 \mathrm{~m}$ Walk Test (second) } & \multicolumn{2}{c}{ Time up and go Test } \\
\cline { 2 - 7 } & pre & post & pre & post & pre & post \\
\hline 1 & -10 & 20 & 18.4 & 16.7 & 17.5 & 14.3 \\
2 & 0 & 25 & 13.8 & 8.5 & 15.4 & 11.7 \\
3 & 0 & 25 & 13.2 & 11.9 & 14.2 & 11.9 \\
4 & -5 & 30 & 26.8 & 20.3 & 24.1 & 18.4 \\
5 & 0 & 20 & 13.5 & 11.0 & 13.9 & 11.4 \\
6 & -5 & 15 & 15.9 & 12.8 & 16.7 & 14.6 \\
7 & 0 & 15 & 14.3 & 12.6 & 14.7 & 13.8 \\
8 & -5 & 10 & 15.3 & 13.9 & 16.0 & 14.5 \\
\hline
\end{tabular}
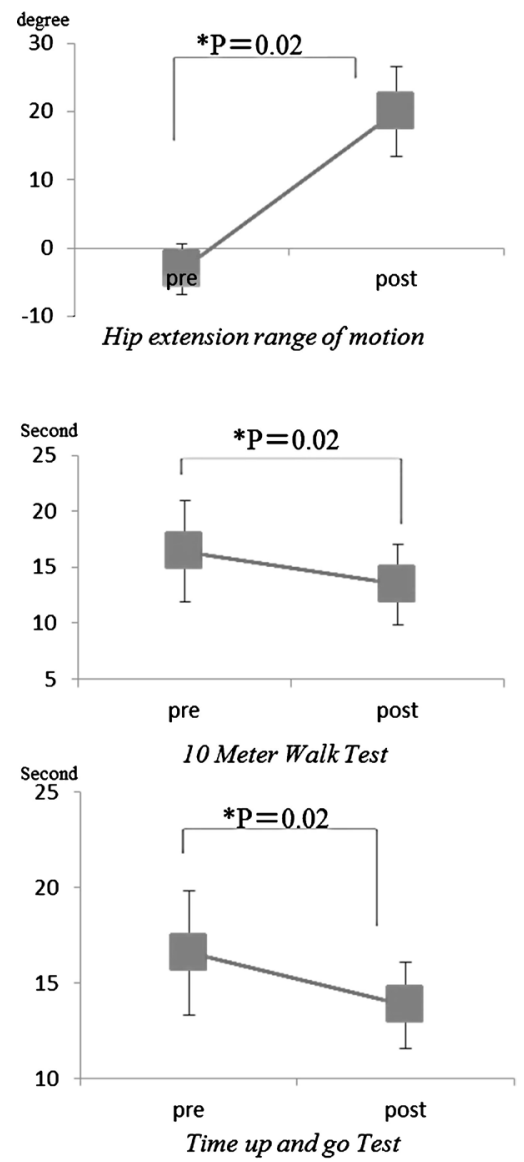

Figure 3. Changes in extension range of motion of hip joint and walking speed and time up and go test. 
between pre-treatment and post-treatment (Wilcoxon signed-rank test $\mathrm{p}<0.05$ ).

\section{Discussion}

Bohannon et al. [8] [16] suggested that the ultimate goal of rehabilitation for patients with stroke is to achieve normal gait pattern and speed. In recent years, it has been reported that the Trailing Limb Angle (TLA), which represents the extension angle of the hip joints during the late stance phase, increases the driving force of the stance phase and improves walking speed [17] [18]. While it has been reported that encouraging the subject to bring the foot on their paralyzed side as far forward as possible is one effective approach to increasing the TLA and promoting an improvement in walking speed [18], because this method assumes that there is no limited range of extension for the hip joints, it is necessary to prioritize improving the range of extension of the hip joints before performing this method. In this research, after providing therapy via $\mathrm{PDH}$ on subjects with a limited range of extension for the hip joints due to stroke hemiplegia, the range of extension for the hip joints improved after just five minutes or less. In addition, after receiving this therapy, the subjects' walking speed improved greatly. This is likely due to the increase in the range of motion for the hip joints causing an increase in the TLA, which resulted in an increase in walking speed. With regards to the mechanism that allows this piston exercise to improve the shortening of the hip joint flexors, rapidly moving the femur head back and forth causes the iliac muscle and psoas major muscle to repeatedly extend and relax in short bursts very rapidly. Because this becomes difficult to relay to the central nerves that control muscle strain as a deep sensation from the proprioceptors in the lower limbs (it is no longer clear what position the lower limbs are in), one can postulate that the muscle strain likely resets, but this is just a hypothesis and requires further verification. Interestingly, the study improved the TUG test for assessing balance ability. Balance impairment is a very common cause of disability in hemiplegic patients [19]. Most hemiplegic patients have difficulties in posture control while walking because of the asymmetrical posture and the abnormal body balance, with reduced knee joint angle and abnormal gait. Previous reports have shown that these patients have an increased risk of falls [20]. Improving the range of motion of hip extension may help improve walking balance. In this study, we developed a piston device for the hip (PDH) that simulates the action of the piston technique for hip joints (PTH), which is a method for improving hip joint flexion range of motion. We then evaluated the efficacy of PDH on 8 spastic hemiplegia patients suffering from a limited range of hip joint flexion. Results confirmed rapid improvement of hip joint range of motion, an improvement in the Time up and Go test, and an increase in walking speed. Hip joint extension range of motion treatment for static hemiplegia patients using PDH is expected to reduce the burden placed on therapists as well as shorten the time required to improve walking function in hemiplegic individuals. 


\section{Summary}

We have developed the piston device for the hip (PDH) that has the effect of increasing the range of motion of hip extension. In this study, PDH was performed in eight patients with spastic hemiplegia who had limited hip joint of range of motion, unstable gait, and slow walking speed. As a result, all patients had increased hip extension range of motion, increased walking speed, and improved gait. PDH can be expected to have the effect of shortening the range of motion of the hip joint in patients with spastic hemiplegia in a short time and improving walking ability.

\section{Acknowledgements}

We are grateful to all the therapists, physicians, and trainers that participated in subject recruitment, evaluation, and training. A special thanks to Professor $\mathrm{Mu}$ nehiro Ikuta for his guidance and participation.

\section{Conflicts of Interest}

The authors declare no conflicts of interest regarding the publication of this paper.

\section{References}

[1] Ministry of Health, Labor and Welfare (year) The Overview of the Patient Survey in 2017. https://www.mhlw.go.jp/toukei/saikin/hw/kanja/17/index.html

[2] Jongbloed, L. (1986) Prediction of Function after Stroke: A Critical Review. Stroke, 17, 765-776. https://doi.org/10.1161/01.STR.17.4.765

[3] Olney, S.J. and Richards, C.L. (1996) Hemiparetic Gait Following Stroke, Part I: Characteristics. Gait Posture, 4, 136-148. https://doi.org/10.1016/0966-6362(96)01063-6

[4] Perry, J., Garrett, M., Granley, J.K. and Mulroy, S.J. (1995) Classification of Walking Handicap in Stroke Population. Stroke, 26, 982-989. https://doi.org/10.1161/01.STR.26.6.982

[5] Wade, D.T. and Hewer, R.L. (1987) Functional Abilities after Stroke: Measurement, Natural History and Prognosis. Journal of Neurology, Neurosurgery, and Psychiatry, 50, 177-182. https://doi.org/10.1136/jnnp.50.2.177

[6] Friedman, P.J. (1990) Gait Recovery after Hemiplegic Stroke. International Disability Studies, 12, 119-122. https://doi.org/10.3109/03790799009166265

[7] Mumma, C.M. (1986) Perceived Losses Following Stroke. Rehabilitation Nursing, 11, 19-22. https://doi.org/10.1002/j.2048-7940.1986.tb00502.x

[8] Bohannon, R.W., Horton, M.G. and Wikholm, J.B. (1991) Importance of Four Variables of Walking to Patients with Stroke. International Journal of Rehabilitation Research, 14, 246-250. https://doi.org/10.1097/00004356-199109000-00010

[9] Yamamoto, S. (2002) Gait Analysis of Patients with Cerebrovascular Disease. Rigakuryoho Kagaku, 17, 3-10. https://doi.org/10.1589/rika.17.3

[10] Lay, A.N., Hass, C.J., Richard Nichols, T., et al. (2007) The Effects of Sloped Surfaces on Locomotion: An Electromyographic Analysis. Journal of Biomechanics, 40, 1276-1285. https://doi.org/10.1016/j.jbiomech.2006.05.023 
[11] Wang, M.S., Tanabe, H., Ooka, K. and Morita, Y. (2017) A Piston Finger Device for Restoring the Motor Function of Chronic Plegic Fingers: Analysis of the Piston Finger Technique. Journal of Robotics, Networking and Artificial Life, 4, 243-247. https://doi.org/10.2991/jrnal.2017.4.3.14

[12] Gajdosik, R.L. and Bohannon, R.W. (1987) Clinical Measurement of Range of Motion: Review of Goniometry Emphasizing Reliability and Validity. Physical Therapy, 67, 1867-1872. https://doi.org/10.1093/ptj/67.12.1867

[13] Tyson, S. and Connell, L. (2009) The Psychometric Properties and Clinical Utility of Measures of Walking and Mobility in Neurological Conditions: A Systematic Review. Clinical Rehabilitation, 23, 1018-1033. https://doi.org/10.1177/0269215509339004

[14] Bohannon, R.W. (1997) Comfortable and Maximum Walking Speed of Adults Aged 20-79 Years: Reference Values and Determinants. Age Ageing, 26, 15-19. https://doi.org/10.1093/ageing/26.1.15

[15] Podsiadlo, D. and Richardson, S. (1991) The Timed "Up and Go" Test: A Test of Basic Functional Mobility for Frail Elderly Persons. Journal of the American Geriatrics Society, 39, 142-148. https://doi.org/10.1111/j.1532-5415.1991.tb01616.x

[16] Bohannon, R.W., Larkin, P.A., Smith, M.B. and Horton, M.G. (1987) Relationship between Static Muscle Strength Deficits and Spasticity in Stroke Patients with Hemiparesis. Physical Therapy, 67, 1068-1071. https://doi.org/10.1093/ptj/67.7.1068

[17] Hsiao, H. and Knar, B.A. (2015) The Relative Contribution of Ankle Moment and Trailing Limb Angle to Propulsive Force during Gait. Human Movement Science, 39, 212-221. https://doi.org/10.1016/j.humov.2014.11.008

[18] Hsiao, H. and Knar, B.A. (2015) Mechanisms to Increase Propulsive Force for Individuals Poststroke. Journal of NeuroEngineering and Rehabilitation, 18, 12-40. https://doi.org/10.1186/s12984-015-0030-8

[19] Tyson, S.F., Hanley, M., Chillala, J., et al. (2006) Balance Disability after Stroke. Physical Therapy, 86, 30-38. https://doi.org/10.1093/ptj/86.1.30

[20] Kwakkel, G., Wagenaar, R.C., Kollen, B.J. and Lankhorst, G.J. (1996) Predicting Disability in Stroke: A Critical Review of the Literature. Age Ageing, 25, 479-489. https://doi.org/10.1093/ageing/25.6.479 